\title{
Vacuna atenuada de Salmonella como vector de antígenos heterólogos
}

\author{
Oscar G. Gómez \\ Center for Vaccine Development, University of Maryland, Baltimore, Maryland, E.E.U.U. \\ Grupo de Microbiología, Instituto Nacional de Salud, Santa Fe de Bogotá, D. C., Colombia
}

\begin{abstract}
Salmonella enterica, serotipo Typhi, es el agente etiológico de la fiebre tifoidea de los habitantes de las regiones más pobres del mundo y es, además, el centro de atención de muchos investigadores dados sus fascinantes mecanismos de invasión, multiplicación intracelular y diseminación intercelular que expresa in vivo e in vitro. Aunque estos mecanismos se asocian directamente con la patogenicidad y la severidad de la enfermedad, las mutaciones definidas en el cromosoma de Salmonella han permitido que estos mecanismos de virulencia se puedan utilizar en beneficio del hospedero. Las mutantes atenuadas de Salmonella son capaces de invadir las células $M$ de la mucosa intestinal y de migrar a las células linfoides del sistema reticuloendotelial donde, en lugar de causar enfermedad, activan eficazmente las respuestas inmunes humoral y celular no sólo contra el microorganismo mismo sino también contra aquellos antígenos heterólogos recombinantes que la bacteria pueda expresar y transportar.
\end{abstract}

En la presente revisión, se discutirán los avances más recientes en el campo de las vacunas vivas atenuadas de Salmonella, su evaluación preclínica y clínica y, también, su aplicación como vector de antígenos. Se darán a conocer las técnicas biomoleculares de clonación y expresión procariótica de las toxinas diftérica, tetánica y de pertusis, así como de los antígenos de Helicobacter pylori y de Plasmodium falciparum. Finalmente, se propone el uso de Salmonella atenuada como vector de vacunas de ADN para expresión eucariótica de los antígenos recombinantes. Los continuos esfuerzos científicos y tecnológicos en el campo de la vacunación con vectores vivos atenuados sugieren que Salmonella es una herramienta potencialmente útil para enfrentar el constante reto de la fiebre tifoidea. Igualmente, los estudios preclínicos y clínicos de fase I demuestran la eficacia de la vacuna de Salmonella viva atenuada como vector de antígenos heterólogos. Se requiere un mayor número de estudios clínicos de fase II y III para demostrar que los vectores de Salmonella podrán formar parte del arsenal de vacunas para la protección de la población mundial contra el constante acecho de los agentes infecciosos emergentes y reemergentes del presente siglo.

Palabras clave: Salmonella, vacuna, DPT, malaria, expresión, antígeno.

\section{Attenuated Salmonella vaccine as a vector for heterologous antigens}

Salmonella enterica, serotype Typhi, is the causing agent of typhoid fever, a disease that affects the inhabitants of the poorest areas in the world. Many researchers have focused their attention on its fascinating cell invasion mechanisms, intracellular multiplication and bacterial intercellular dissemination expressed in vivo and in vitro. Although the above mechanisms are directly associated with pathogenicity and disease severity, defined mutations in the Salmonella chromosome have allowed the use of these virulence mechanisms in benefit of the mammalian host. Attenuated Salmonella mutants are still able to invade M cells of the intestinal mucosa and to migrate to the lymphoid cells of the reticuloendothelial system. Once inside the host, the attenuated Salmonella is unable to cause disease, instead, it effectively activates the humoral and cellular immune responses not only towards the Salmonella antigens themselves but also to the recombinant heterologous antigens being expressed and delivered by the bacteria. In 
the present review, recent advances in the field of live attenuated Salmonella vaccines will be discussed; the preclinical and clinical data will be evaluated, and the clinical application as antigen delivery systems will be anticipated. Information will be given on current molecular biology techniques on cloning and prokaryotic expression of tetanus, diphtheria and pertussis toxins, as well as Helicobacter pylori and Plasmodium falciparum antigens. Similarly, the use of attenuated Salmonella as a vector for DNA vaccine delivery and further eukaryotic expression of recombinant antigens will be proposed. Continuous scientific and technological efforts in the field of vaccination with live attenuated vectors suggest that Salmonella is a promising weapon to face the challenge imposed by typhoid fever. Similarly, preclinical and phase I clinical studies indicate how efficient live attenuated Salmonella vaccines may be as a delivery system for heterologous antigens. More phase II and phase III clinical studies will be necessary to demonstrate that Salmonella vectors may be part of the vaccine arsenal capable of protecting the world population against the constant risk of infectious diseases due to emergent and reemergent microorganisms.

Key words: Salmonella, vaccine, DPT, malaria, expression, antigen.

Salmonella es una enterobacteria Gram negativa con una especie patógena para el hombre, $S$. enterica. Un elevado número de serotipos hace parte de esta especie; la mayoría están asociados, principalmente, a patologia gastrointestinal, dentro de los cuales se destacan los serotipos Typhimurium, Paratyphi, Enteritidis y Heidelberg (1). Otros serotipos, en cambio, se asocian con bacteremia y septicemia; el representante más importante es $S$. enterica, serotipo Typhi $(2,3)$. EI serotipo Typhi es el agente causal de la fiebre tifoidea, una enfermedad que afecta predominantemente a los países en vías de desarrollo, especialmente a niños en edad escolar que viven en sitios con carencia de servicios de acueducto, alcantarillado y agua potable (4). S. enterica, serotipo Typhi, ingresa al hospedero por la vía oral e invade y destruye las células $M$ del tejido linfoide de la musosa intestinal para, luego, diseminarse por vía sanguínea a todos los órganos del sistema reticuloendotelial (5).

El hospedero puede inducir una respuesta inmune contra el microorganismo invasor y, al cabo de varias semanas, eliminarlo completamente o limitar su virulencia y convertirlo en un comensal más de la flora gastrointetinal. O, también, la bacteria invasora continúa diseminándose hasta causar

Correspondencia:

Center for Vaccine Development, Division of Geographic Medicine, 685 West Baltimore Street, Baltimore, Maryland, U.S.A., 21201-1509

email: ogomez@umppa1.ab.umd.edu

Recibido: 08/02/00; aceptado: 28/04/00 daño multisistémico que puede causar la muerte del paciente. Se estima una incidencia mundial anual de 30 millones de casos de fiebre tifoidea, con 600.000 muertes $(6,7)$. En algunas regiones de Africa y Asia, la mortalidad puede alcanzar cifras de $30 \%$, mientras que, en Estados Unidos y otros países industrializados, la mortalidad no sobrepasa el $1 \%$ (8). Aunque la fiebre tifoidea se puede tratar eficazmente con antibióticos, existe preocupación por el elevado número de cepas resistentes a los antibióticos que se han aislado en países del Medio Oriente, India y el suroriente asiático (9). Las vacunas contra Salmonella capaces de prevenir la fiebre tifoidea se han constituido en una prioridad de salud pública para las regiones más pobres del mundo donde la enfermedad es endémica y las medidas que tengan una relación costo-beneficio favorable, constituyen la única alternativa eficaz para proteger a la población contra esta enfermedad.

Varios factores de virulencia le permiten a Salmonella colonizar, invadir e, inclusive, eliminar al hospedero. Entre ellos se destacan las dos islas de patogenicidad que le confieren al microorganismo la capacidad invasora y de supervivencia dentro de los macrófagos. Las islas de patogenicidad son fragmentos de ADN de tamaño variable que, al incorporase al cromosoma bacteriano, aportan información genética que contribuye a la patogenicidad de la bacteria receptora (10). Las islas de patogenicidad se trasmiten genéticamente de manera horizontal mediante bacteriófagos provenientes de diversas 
especies bacterianas. Cada una de ellas codifica un sistema de secreción tipo III con funciones definidas. Mientras que una de las islas de patogenicidad, a través del sistema de secreción tipo III, le permite a Salmonella transportar factores de invasión bacteriana al espacio extracelular para facilitar la internalización del microorganismo a las células epiteliales in vivo e in vitro (11-13), la segunda isla de patogenicidad le permite multiplicarse dentro de los macrófagos $(14,15)$ y evadir la respuesta inmune del hospedero.

\section{Respuesta inmune contra la infección por Salmonella}

La afinidad de Salmonella por las células del sistema inmune es responsable, en gran parte, de la inducción de la respuesta inmune que le permite a los individuos infectados sobrevivir a la infección. Se ha informado que las cepas vivas de Salmonella atenuada inducen eficientemente la respuesta humoral inmune y la inmunidad celular no sólo a nivel sistémico sino también a nivel local, en las mucosas (16-19). La respuesta celular inmune restringida por el complejo mayor de histocompatibilidad $(\mathrm{CMH})$ clase Il y mediada por linfocitos T CD4-positivos, puede ser de tipo.T1 ayudadora (Th1) o T2 ayudadora (Th2). La respuesta Th1 se caracteriza por la liberación de interferón gamma (20) e IL-2, mientras que la de tipo Th2 se caracteriza por la liberación de IL-10. La actividad de estas citocinas permite la producción de títulos elevados de anticuerpos séricos y en mucosas durante los procesos infecciosos $(19,21)$. Además de la respuesta celular restringida por $\mathrm{CMH}$ clase $\mathrm{II}$, se ha informado sobre la respuesta immune restringida por el CMH clase I mediada por linfocitos T CD8, los cuales dan lugar al desarrollo de T citotóxicos (CTL) asociados con la inmunoprotección contra Salmonella en ratones y en humanos (figura 1) $(18,22)$. Una buena respuesta Th1 con memoria inmunológica contra la infección por Salmonella,

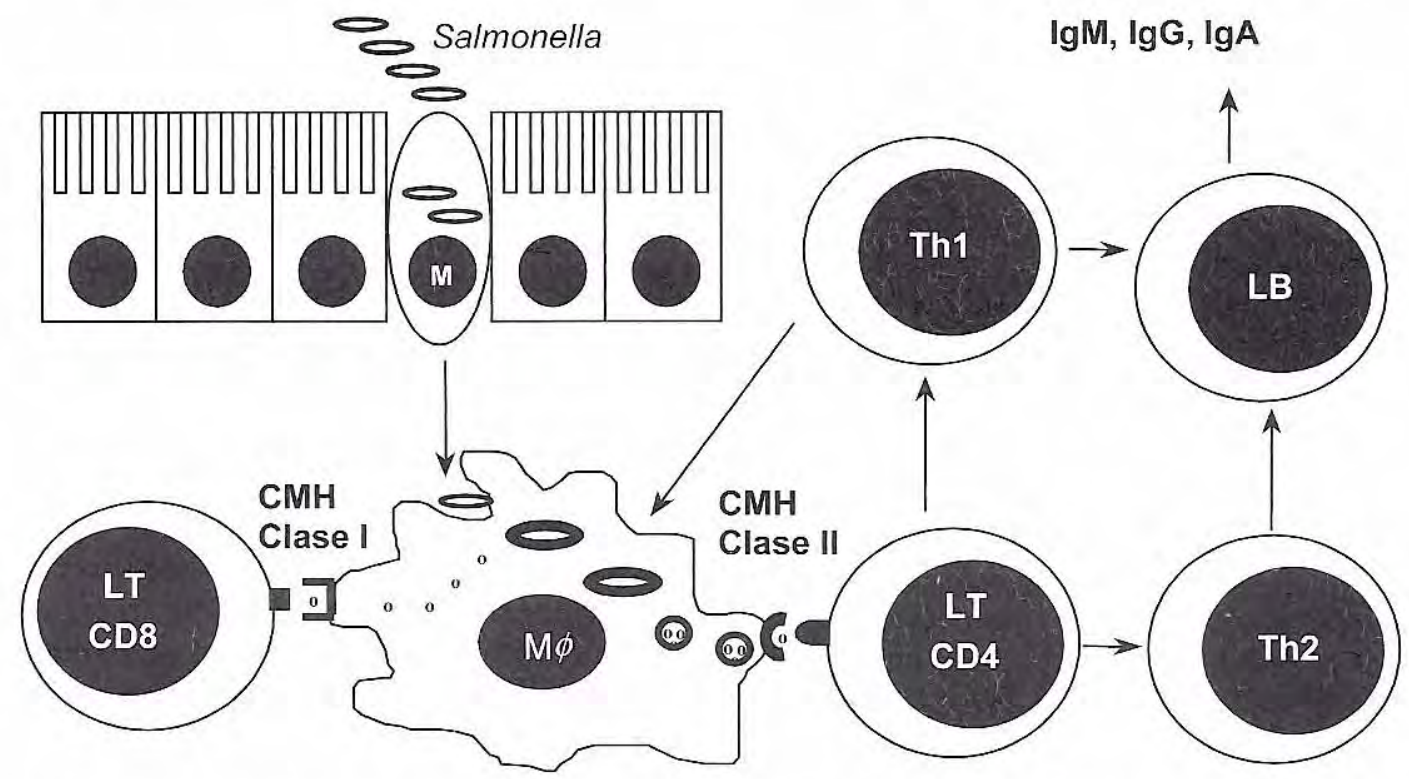

Figura 1. Diagrama de la respuesta immune inducida por Salmonella. Salmonella invade las células M de la mucosa intestinal y migra posteriormente a los macrófagos, donde se procesan los antígenos bacterianos. Los antigenos procesados dentro de los fagolisosomas forman péptidos que son presentados por moléculas del CMH de clase II a linfocitos T CD4, los cuales, a su vez, activan el desarrollo de linfocitos T ayudadores Th1 y Th2. Los linfocitos Th1 y Th2 producen citocinas especificas y estimulan la secreción de anticuerpos específicos de diversos isotipos a partir de linfocitos $\mathrm{B}$. Algunos antigenos procesados son liberados fuera de los fagolisosomas para ser presentados por moléculas CMH clase I a linfocitos T CD8 y, así, inducir la producción de linfocitos $T$ citotóxicos específicos.

LT: linfocitos T; LB: linfocitos B; CPA: células presentadoras de antigeno; $\mathrm{M}$ : células $\mathrm{M} ; \mathrm{M} \phi$ : macrófago; $\mathrm{CMH}$ : complejo mayor de histocompatibilidad. 
requiere la integridad de la respuesta inmune mediada por linfocitos $B$. Los ratones transgénicos con mutaciones en genes esenciales para la respuesta inmune tipo $B$, son incapaces de generar una respuesta protectora duradera contra Salmonella (23).

\section{Vacuna contra Salmonella}

La alta incidencia de infecciones por Salmonella en los países en vías de desarrollo y el alto riesgo de infección para viajeros y microbiólogos clínicos, ha incrementado el interés en desarrollar vacunas contra Salmonella. Se han desarrollado dos tipos de vacuna para inducir protección contra la fiebre tifoidea: las vacunas parenterales de bacteria muerta y las vacunas orales vivas (24).

\section{Vacunas parenterales de bacteria muerta}

Las vacunas de bacterias muertas, inactivadas por calor y preservadas en fenol, fueron una de las primeras vacunas contra Salmonella desarrolladas para uso parenteral. La protección inducida por esta vacuna fue de 60 a $67 \%$, con una duración hasta de 7 años. Sus mayores desventajas fueron las reacciones adversas severas con manifestaciones locales y sistémicas en $25 \%$ de los vacunados (25), lo que motivó su abandono.

Otro tipo de vacuna es la de antígenos capsulares de polisacáridos, cuyos altos niveles de protección $y$ efectos adversos insignificantes le ha garantizado una alta aceptación (26). Su mayor desventaja es la corta duración de la respuesta humoral en niños de 2 a 5 años y su ineficacia en los menores de 2 años. En la actualidad, se están evaluando los conjugados del polisacárido con proteínas recombinantes capaces de activar la respuesta celular de linfocitos $\mathrm{T}$ y de inducir memoria inmunológica (27). Actualmente, la vacuna de polisacáridos capsulares ya ha sido aprobada para su uso parenteral.

\section{Vacunas orales con bacteria viva}

La nueva generación de vacunas orales contra Salmonella utilizan cepas vivas atenuadas. La primera vacuna oral viva atenuada, serotipo Typhi, en obtener licencia para uso en humanos fue la vacuna Ty21a. Esta vacuna es un derivado de la cepa Ty2, un aislamiento clínico de S. enterica, serotipo Typhi, la cual fue mutada químicamente para obtener un fenotipo atenuado. Varios estudios clínicos indicaron que esta cepa atenuada era capaz de conferir protección en un alto número de voluntarios, en quienes se usó el placebo como control. Igualmente, la Ty21a indujo protección en extensos estudios de campo controlados con placebo en Egipto, Chile e Indonesia (28- 30). La protección conferida por esta vacuna puede durar de 5 a 7 años a pesar de la modesta respuesta inmune que induce. Además, es una vacuna bien tolerada con un bajo índice de reacciones adversas. Las nuevas vacunas de Salmonella atenuada incluyen mutaciones definidas molecularmente en genes necesarios para el metabolismo de la bacteria $(31,32)$, como también en genes de virulencia (33).

\section{Tipo de vacunas vivas atenuadas de Salmonella}

Las cepas de Salmonella atenuada se obtienen a partir de mutantes en genes involucrados en el metabolismo bacteriano y en la replicación del ADN. Dichas mutaciones afectan la capacidad de la bacteria de multiplicarse dentro del hospedero, convirtiéndola en un cepa avirulenta. Sin embargo, la atenuación no afecta la capacidad invasora de la bacteria ni su diseminación en el sistema reticuloendotelial, ni su habilidad de inducir respuestas inmunes en el hospedero. La bacteria atenuada tiene poca capacidad de multiplicarse $y$, una vez dentro del hospedero, es rápidamente eliminada de la circulación sin que tenga oportunidad de inducir enfermedad. Los genes blanco más comúnmente mutados con el fin de lograr atenuación bacteriana son los genes aromáticos (aro) (32). Estos genes codifican enzimas necesarias para la síntesis de aminoácidos, vitaminas y agentes quelantes de hierro. Debido a que muchos de estos componentes son limitados en el hospedero mamífero, la falta de estas enzimas biosintéticas limitan el crecimiento bacteriano postinfección.

La cepa de $S$. enterica, serotipo Typhimurium, SL3261 es una mutante en el gen aro $A$, con virulencia atenuada en ratones y con capacidad de inducir protección contra un reto letal con la cepa silvestre de serotipo Typhimurium (31). La vacuna SL3261 se ha usado extensamente como 
vector de diversos genes heterólogos. Un representante de las vacunas de $S$. enterica, serotipo Typhi, es la cepa CVD 908htrA, un doble mutante de genes aromáticos aroC y aro $D$ con una mutación adicional en el gen htrA $(32,34)$. Ambas mutaciones aro generan una cepa atenuada que, al ser administrada oralmente a voluntarios, induce una respuesta inmune humoral y celular fuerte asociada con protección. La mutación en $h$ trA bloquea la expresión de la serinproteasa $\mathrm{HtrA}$, una proteína de estrés que contribuye a la patogenicidad de la bacteria. La vacuna CVD 908htrA, que se está utilizando como vector de antígenos heterólogos, ha mostrado un buen nivel de tolerancia en las pruebas con voluntarios.

Otras mutaciones en genes metabólicos evaluados in vivo incluyen los genes cya, crp, phoP, phoQ y htrA. Los genes cya y crp son necesarios para la síntesis del AMP cíclico y su receptor, respectivamente, y participan en la regulación de múltiples vías metabólicas y en el control de la expresión genética de los diversos genes y operones. En forma similar, los genes phoP y phoQ, miembros del sistema de regulación de dos componentes, han sido mutados para la creación de cepas atenuadas. Este sistema activa la expresión genética de la transcripción de los múltiples genes, incluidos los genes de virulencia en la respuesta a cambios en el nivel de fosfato (2).

\section{Uso de Salmonella viva atenuada como vector de antígenos}

Se han utilizado exitosamente antígenos de origen viral, bacteriano y parasitario en Salmonella en modelos animales como activadores de respuesta inmune para inducir la protección contra diversos patógenos (36). En esta sección, se describe la expresión de antígenos procedentes de patógenos humanos en Salmonella, su evaluación en modelos animales como agentes immunoprotectores y su bioseguridad e inmunogenicidad en estudios clínicos de fase I.

\section{Salmonella como vector en la vacunación contra tétanos, difteria y pertusis}

La vacuna de DPT es un combinado de toxoide tetánico, diftérico y antígenos de Bordetella pertusis. La vacuna se da por vía parenteral y requiere de más de 3 refuerzos para la protección apropiada del individuo. Aunque la vacuna es efectiva y de bajo costo, presenta efectos colaterales locales y sistémicos, algunos severos, relacionados principalmente con los antígenos de B. pertusis. Además, la inmunización parenteral crea riesgos de transmisión de otras enfermedades infecciosas como la hepatitis $B$ y el virus de la inmunodeficiencia humana, en especial, en países donde aún prevalece la reutilización de las agujas hipodérmicas.

Una vacuna ideal contra estas enfermedades sería aquélla que pudiera administrarse oralmente, de bajo costo y que no requiriera más de dos refuerzos. Durante los últimos años se ha explorado la posibilidad de crear tal vacuna, utilizando Salmonella como vector de estos antígenos. El fragmento $\mathrm{C}$ de la toxina tetánica, una porción altamente inmunogénica y carente de toxicidad, ha sido clonado y expresado en Salmonella bajo el control de diversos promotores inducibles in vivo, los promotores nirB, pagC y katG (37). La inmunización de ratones con Salmonella que expresa este antígeno, induce elevados niveles de anticuerpos neutralizantes capaces de proteger contra un reto experimental de toxina tetánica $(16,38)$. La inmunogenicidad del fragmento $\mathrm{C}$ que expresa $S$. enterica, serotipo Typhi, ha sido altamente eficiente cuando se inmunizan los ratones por vía intranasal (16). Esta vía de inmunización activa principalmente el tejido linfoide nasal y, también, alcanza a estimular el tejido linfoide pulmonar, las placas de Peyer y el bazo (39).

Mientras que la expresión del fragmento $\mathrm{C}$ de la toxina tetánica (TT) en Salmonella ha sido indiscutiblemente exitosa, la expresión procariótica de porciones no toxigénicas de la toxina diftérica ha sido extremadamente difícil. La toxina diftérica (TD) es una proteína de 535 aminoácidos con tres dominios y una región carboxilo terminal responsable de la unión a los receptores de membrana de la células eucarióticas, capaz de inducir la endocitosis de la toxina en la célula (40). Con el fin de expresar la región C-terminal de la TD con la misma eficiencia que el fragmento $C$ de la TT, se creó un sistema de expresión basado en 
el plásmido pTETnir15, el cual porta el gen para el fragmento $\mathrm{C}$ de la TT bajo el control del promotor nirB. La porción 3' del fragmento C se modificó adicionando una región bisagra consistente en codones de Gli y Pro y dos sitios de reconocimiento de enzimas de restricción. El plásmido resultante, denominado pOG214 (figura 2), se utilizó para crear una fusión de traducción entre el fragmento $C$ de TT y la region C-terminal de TD, que expresara una sola proteína con ambas regiones toxigénicas bajo el control del promotor nirB. El plásmido resultante, pOG215, expresó la fusión de fragmento $\mathrm{C}$ de TT y la región $\mathrm{C}$-terminal de DT no sólo en E. coli sino también en Salmonella (41). La fusión proteica fue reconocida en immuno- blots no sólo con anticuerpos específicos contra la TT sino también con anticuerpos contra la TD.

El sistema de expresión de fusión con fragmento C (figura 2), se utilizó en forma similar para expresar la subunidad $\mathrm{S} 1$ de la toxina de $B$. pertusis (TP) (41,42). La TP es un factor de virulencia esencial en la patogénesis de la enfermedad y se considera un componente imprescindible para el desarrollo de la nueva vacuna acelular de DPT. La toxina está compuesta de cinco subunidades, S1 a S5, siendo la subunidad S1 la región portadora de la actividad adeniladora, responsable directa de la toxicidad celular. Las subunidades S2 a S5 forman la región

A

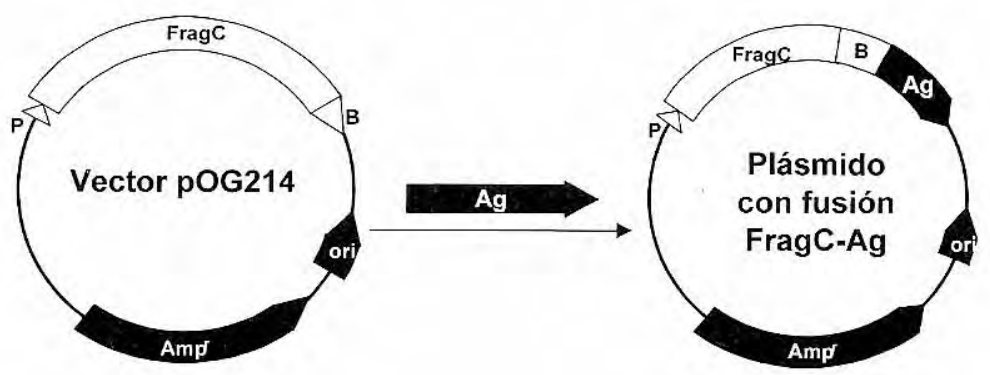

B

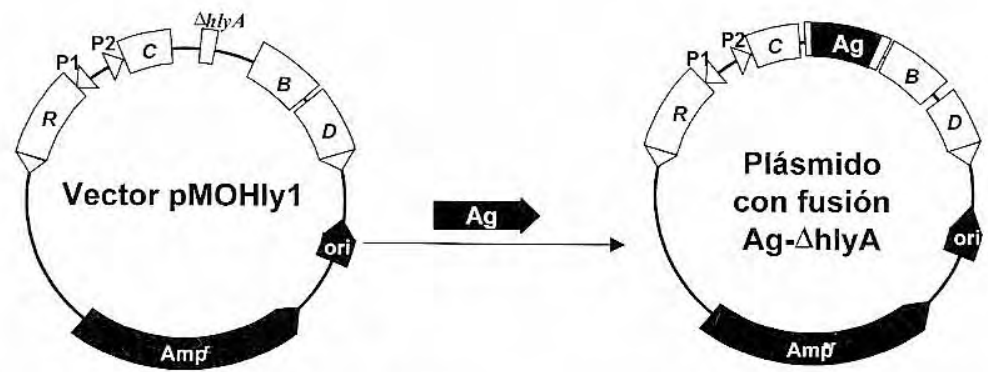

Figura 2. Vectores para expresión de antígenos. Panel A. Sistema de expresión intracitosólica de antigenos. El sistema consiste en un vector llamado pOG214 que posee el gen del fragmento C de la TT con una región bisagra (B) en la porción 3' terminal, a la cual se le pueden clonar, en marco de lectura, genes que codifiquen para antígenos heterólogos (Ag). La región bisagra $(\mathrm{B})$, que codifica residuos de Gli y Pro, le permitirá a la proteína fusionada $(\mathrm{Ag})$ movilizarse libremente mientras esté unida al fragmento $C$. Como el fragmento $C$ y la región $B$ carecen de señales de secreción, la proteína de fusión expresada por el plásmido permanecerá dentro del citosol bacteriano. P es el promotor para el gen fragmento $\mathrm{C}$ o su fusión. Panel B. Sistema para expresión y secreción de antígenos. El vector pMOHly1 contiene el operón de la hemolisina de $E$. coli, el cual codifica un sistema de secreción tipo I. Las proteínas codificadas por los genes hly $B(B)$ y hylD (D) permiten, junto con la proteína de Salmonella TolC, la translocación de la HlyA o de proteinas que contengan la señal de secreción de la HlyA $(\triangle \mathrm{HlyA})$ al espacio extracelular bacteriano (69). El gen que codifica el antígeno heterólogo $(\mathrm{Ag})$ deberá clonarse en marco de lectura con la señal de secreción $\triangle$ HlyA en la region 3' terminal. HlyR $(R)$ es el activador del promotor P2 que permite la transcripción de los genes hlyB (B), hlyC (C), ÄhlyA, y hlyD (D). P1 es el promotor para el gen hlyR (R). Amp' es el gen que codifica para beta-lactamasa, el marcador de resistencia antibiótica de los plásmidos. Ori es un origen de replicación ColE1 presente en ambos vectores. 
que se une a los receptores de membrana de las células eucariotas blanco y que permite la internalización de la subunidad S1. La fusión TTS1 se expresó en Salmonella bajo el control del promotor nirB, como se demostró en los immunoblots. La Salmonella que expresa la fusión se utilizó para inmunizar ratones y se demostró que el suero de los ratones inmunizados presentaba anticuerpos neutralizantes específicos contra la subunidad S1. El desarrollo de nuevas vacunas de Salmonella como vector de DPT y su posterior evaluación en voluntarios permitirá concluir si es posible contar en el futuro con vacunas más eficaces, más seguras y menos costosas contra la difteria, el tétanos y la Tos ferina.

\section{Vacuna de Salmonella contra infecciones por Helicobacter pylori}

Las infecciones por $H$. pylori se asocian con un significativo número de enfermedades gastrointestinales, entre las cuales se destacan la gastritis crónica, la úlcera péptica, el adenocarcinoma gástrico y el linfoma gástrico (43-46). El elevado número de individuos infectados, el incremento de la resistencia de las cepas a los antibióticos y el alto costo del tratamiento antibiótico, en especial en los países en vías de desarrollo, son factores preocupantes que justifican el desarrollo de alternativas costoefectivas, para el control y la prevención de la infección por H. pylori, como son las vacunas.

La ureasa, una enzima esencial para el proceso de colonización de $H$. pylori, ha sido evaluada como vacuna en ratones en forma de proteína purificada en combinación con la toxina colérica $(47,48)$. Varios estudios informan que dicha combinación es inmunoprotectora contra la colonización de la mucosa gástrica murina por $H$. pylori (49-51). Las subunidades $A$ y $B$, que conforman la ureasa de H. pylori (52), fueron clonadas y expresadas en la cepa atenuada de $S$. enterica, serotipo Typhimurium, SL3261. El plásmido pYZ97, donde los genes de la ureasa A y $B$ fueron clonados, es un derivado del vector $\mathrm{pBR} 322$, el cual demostró ser altamente estable tanto in vitro como in vivo.

Igualmente, la vacuna atenuada SL3261 (pYZ97) expresó un nivel significativamente alto de ambas subunidades como se demostró en los immunoblots (53-54). La inmunogenicidad de esta vacuna se evaluó inmunizando dos tipos de cepas de ratones, BALB/c y C57BL6, por vía oral, con una dosis única de $1 \times 10^{9}$ unidades formadoras de colonias (UFC) en un volumen total de 100 ul. Los immunoblots y los ensayos de ELISA mostraron que ambas cepas de ratones inmunizados con la vacuna SL3261 (pYZ97) respondían con anticuerpos antiureasa $A$ y antiureasa $B$ de tipo $\lg G e$ $\lg A$. Se encontró que la respuesta humoral fue comparable en ambas cepas de ratones no sólo en las mucosas sino también a nivel sistémico.

No se observaron anticuerpos antiureasa en ratones inmunizados con la cepa control SL3261. Aquellos ratones inmunizados con la cepa SL3261 (pYZ97) mostraron un nivel de protección de $100 \%$ contra la colonización gástrica por una cepa silvestre de $H$. pylori adaptada a ratones. La alta efectividad de la vacuna en la protección contra la colonización gástrica por $H$. pylorien el modelo murino, la alta inmunogenicidad y los efectos colaterales insignificantes, hacen de la vacuna viva atenuada recombinante de Salmonella una buena alternativa para el control de las enfermedades en los humanos asociadas con la infección por $H$. pylori.

\section{Vacunas de Salmonella contra malaria}

La malaria es una enfermedad de reconocida importancia en la salud pública de los países tropicales, ya que es responsable de 2 millones de muertes anuales, aproximadamente, y cerca de 300 millones de casos nuevos anuales de infección (55). La diseminación de cepas de Plasmodium falciparum con resistencia a la nueva generación de drogas antimaláricas ha generado un serio problema para el tratamiento de pacientes y para el control de la malaria, especialmente en el suroriente asiático $(56,57)$.

Las vacunas, desde el punto de vista de la salud pública, constituyen el método más eficaz de prevención y control de enfermedades infecciosas. Infortunadamente, las dificultades en el desarrollo de vacunas antimaláricas se ha hecho evidente como consecuencia del complejo ciclo de vida del parásito, la expresión alternante de genes para cada fase de desarrollo y la diversidad antigénica debida a la variación de fase (58), así como al 
intercambio genético durante el ciclo sexual del parásito en el mosquito (59).

Dentro del hospedero humano, el parásito transita por el hígado donde se lleva a cabo la fase preeritrocítica. Posteriormente, el parásito migra a la sangre periférica, donde tiene lugar la fase eritrocítica, la cual se manifiesta clínicamente en el paciente con rangos de severidad que van desde la fiebre y los escalofríos hasta el bloqueo de la red capilar, el daño multisistémico y la muerte del paciente (60).

Los mecanismos de respuesta inmune antimalárica no se han dilucidado completamente; pero se sabe que juegan un papel primordial para el control de la enfermedad, como se evidencia en los estudios epidemiológicos experimentales. Estos informan que la inmunicidad natural en la población adulta de áreas hiperendémicas es capaz de inducir un alto grado de protección contra la malaria (61). Los estudios experimentales han mostrado, igualmente, que la immunización de individuos con esporozoítos irradiados es efectiva para inducir protección contra el reto experimental con cepas silvestres de $P$. falciparum $(62,63)$. Estas evidencias clínicas indican que la vacunación contra la malaria es posible y que constituye una alternativa ideal para su control (64).

El tipo de respuesta inmune que posiblemente participa en la protección antimalárica durante la fase preeritrocítica es la respuesta celular inmune de tipo citotóxico (65). Las células citotóxicas destruyen las células hepáticas infectadas, liberan el parásito al espacio extracelular y lo exponen directamente a la acción de macrófagos y anticuerpos específicos para su posterior eliminación. Además, la respuesta inmune de anticuerpos se considera esencial para la inhibición de la invasión de hepatocitos por los esporozoítos y el consecuente bloqueo de las fases sucesivas de desarrollo parasitario. Durante la fase eritrocítica, la respuesta de anticuerpos juega un papel primordial en la inhibición de la invasión de los eritrocitos por los merozoítos mediante el bloqueo de las proteínas de superficie del merozoíto que se unen a los receptores de la membrana del eritrocito (66). Dichos anticuerpos también podrian eliminar los merozoítos circulantes por medio de la fijación del complemento o a través de un mecanismo de citotoxicidad mediada por anticuerpos.

\section{Expresión y secreción de antígenos preeritrocíticos de $P$. falciparum}

La proteína 2 de superficie del esporozoíto de $P$. falciparum (SSP-2) se informó como un antígeno protector en ratones contra la infección experimental por malaria. La proteína induce linfocitos T citótoxicos (CTL) específicos, responsables de la protección contra la infección experimental con parásitos virulentos (65). Los CTL específicos contra SSP-2 han sido detectados también en voluntarios inmunizados con esporozoítos irradiados de $P$. falciparum y se cree que pueden participar en la inmunoprotección antimalárica en las áreas endémicas (67).

Con el objetivo de inducir CTL específicos para SSP-2, se clonó y expresó la SSP-2 de $P$. falciparum en la vacuna de $S$. enterica, serotipo Typhi, CVD 908htrA (68). El sistema de expresión utilizado fue el de secreción tipo I de la hemolisina, derivado originalmente de una cepa de $E$. Scherichia coli uropatogénica (69) (figura 2, panel B). A través de este sistema, la proteína SSP-2 se fusiona a una secuencia de la señal de secreción que es reconocida por proteínas del sistema de secreción localizadas en la pared celular bacteriana, las cuales transportan la SSP2 al espacio extracelular. Se ha informado que la secreción de antígenos mediante este sistema de expresión induce una fuerte respuesta específica de CTL, esencial para la inmunoprotección contra los parásitos intracelulares (70).

El antígeno de fase hepática (LSA-1) de $P$. falciparum contiene epítopes inductores de respuesta immune $T$ y $B$ en individuos expuestos a malaria, los cuales se cree que participan activamente en la immunoprotección $(71,72)$. Este antígeno también ha sido expresado en Salmonella, no sólo a través del sistema de secreción tipo I sino también como fusión con el fragmento $\mathrm{C}$ de la toxina tetánica (73) (figura 2). Los experimentos en el modelo murino mostraron que la inmunización con Salmonella, que expresa LSA, induce no sólo anticuerpos específicos contra LSA-1 sino también CTL. 
Otra proteína preeritrocítica de interés es la proteína circunsporozoítica (CSP), expresada en la vacuna viva $S$. enterica, serotipo Typhi, CVD 908 a partir de una inserción en el cromosoma bacteriano bajo el control de un promotor pTac. Tres de doce voluntarios inmunizados con esta cepa respondieron con anticuerpos o con CTL. Aunque el número de voluntarios que respondió al CSP fue bajo, el estudio demostró que Salmonella no sólo expresaba CSP in vivo sino que también tenía la posibilidad de estimular respuestas inmunes de tipo humoral y celular (22). En la actualidad, nuestro laboratorio evalúa la expresión de CSP a partir de plásmidos multicopia y promotores para inducción in vivo, con el fin de incrementar la expresión de CSP y estimular una mejor respuesta inmune en el hospedero.

\section{Expresión de proteínas de la fase eritrocítica de $P$. falciparum}

La proteína de superficie del merozoíto (MSP-1) tiene $200 \mathrm{kDa}$ y es una buena candidata para ser incluida en la vacuna antimalárica multivalente (7476). La proteína es procesada por una enzima maturasa que genera un fragmento de $19 \mathrm{kDa}$ que permanece asociado con la membrana del merozoíto (77). Este fragmento, denominado MSP-1 ${ }_{19}$, contiene dos motivos presentes también en el factor de crecimiento epidérmico (EGF), que le permiten al merozoíto adherirse $y$, posteriormente, invadir el eritrocito. Los anticuerpos neutralizantes anti-MSP- ${ }_{19}$ previenen el proceso de invasión de eritrocitos in vitro y protegen a los ratones contra la infección experimental por malaria $(75,78)$.

En nuestro laboratorio, hemos clonado y expresado exitosamente la proteína MSP-1 fusionada al fragmento $\mathrm{C}$ de la toxina tetánica bajo el control del promotor nirB en Salmonella (79) (figura 2, panel A). La inmunogenicidad de la vacuna viva CVD 908htrA que expresa el fragmento C-MSP-1, se evaluó en ratones BALB/c mediante inmunización intranasal de $1,0 \times 10^{9}$ UFC de la vacuna. Los ensayos de ELISA del suero de los ratones evaluados indicaron que los ratones elaboraban anticuerpos anti-MSP-1 ${ }_{19}$ y antifragmento $\mathrm{C}$ de la TT, los cuales aumentaron en título después de un refuerzo con la misma dosis intranasal de la vacuna. Los sueros se evaluaron, además, por inmunofluorescencia y se demostró que los anticuerpos presentes en dichos sueros reconocian la estructura nativa del MSP-1 sobre la superficie de los merozoítos (79). Estos resultados indican que la proteina MSP-1 expresada en Salmonella, lo hace también in vivo e induce una respuesta inmune de anticuerpos contra epítopes nativos de MSP-1. Estos resultados crean la posibilidad de explorar el potencial de esta vacuna como componente eritrocítico de una vacuna polivalente de Salmonella contra malaria.

\section{Conclusiones y perspectivas}

La atenuación de agentes patógenos ha sido el concepto central a lo largo de la historia de la vacunación. El uso del agente agresor sin poder virulento es el paradigma en el cual se basan muchas de las vacunas de uso en la actualidad. Algunos ejemplos incluyen las vacunas vivas contra la poliomielitis, la rabia y la fiebre tifoidea, como también toxinas atenuadas o toxoides contra el tétanos, la difteria y, próximamente, contra la tos ferina.

Las vacunas de Salmonella atenuada son un sistema versátil para el transporte de antígenos heterólogos de origen viral, bacteriano y parasitario, para la inducción de respuestas inmunoprotectoras de tipo humoral y celular en el hospedero humano. Igualmente, se ha propuesto el uso de Salmonella para expresar antígenos tumorales y agentes modificadores de la respuesta inmune, como las citocinas, con el fin de explorar su utilidad en el tratamiento de cáncer. Sistemas novedosos de expresión procariótica han permitido la expresión de antígenos dentro del citosol bacteriano, como también en el espacio extracelular mediante un sistema de secreción a través de membrana. Cada sistema presenta el antígeno al sistema inmunitario en forma particular e induce la activación de subpoblaciones linfocíticas divergentes de tipo Th1, Th2 o CTL. Según el agente infeccioso, se podrían elegir sistemas de expresión y secreción que indujeran respuestas predominantemente humorales tendientes a la eliminación del microorganismo extracelular, o respuestas predominantemente celulares para la eliminación del microorganismo intracelular. 
Actualmente se evalúan nuevas estrategias para el uso de Salmonella como vector y, entre las más prometedoras, se incluye el transporte de vacunas de ADN con Salmonella (80). Las vacunas de ADN son, por lo general, plásmidos que portan un gen bajo el control de un promotor eucariote, el cual codifica un antígeno recombinante. Salmonella atenuada transporta dicho plásmido al sistema reticuloendotelial donde es liberado intracelularmente para iniciar la expresión eucariótica del antígeno recombinante. El antígeno expresado es procesado y presentado por moleculas clase I del $\mathrm{CMH}$ a los receptores celulares $\mathrm{T}$ de linfocitos T CD8. La activación de los linfocitos T CD8 induce la estimulación de células CTL específicas, capaces de eliminar aquellas células que presenten sobre su superficie epítopes del mismo antígeno. Este sistema de inmunización será útil en la elaboración de vacunas contra parásitos intracelulares como la malaria en la fase preeritrocítica, la tuberculosis o los agentes virales, entre otros.

El constante avance tecnológico y científico permitirá determinar si Salmonella atenuada podrá constituirse en un vector eficaz de vacunas para la protección contra diversos patógenos microbianos. El alto nivel de seguridad para el vacunado, la ventaja de su administración oral, la inducción eficaz de la respuesta inmune y el bajo costo de producción son factores contundentes en favor del desarrollo de vacunas de Salmonella, en especial para aquellas regiones del mundo donde el índice de enfermedades infecciosas es elevado y donde los recursos para la salud son limitados o casi inexistentes.

\section{Agradecimientos}

Al doctor Myron M. Levine por su invaluable apoyo en el desarrollo del presente trabajo, el cual fue financiado parcialmente con los fondos RO 1Al40292 y RO 1AI29471 del NIAI de los National Institutes of Health.

\section{Referencias}

1. Khakhria R, Woodward D, Johnson WM, Poppe C. Salmonella isolated from humans, animals and other sources in Canada, 1983-92. Epidemiol Infect 1997; 119:15-23.

2. Hohmann EL, Oletta CA, Killeen KP, Miller SI. phoP/ phoQ-deleted Salmonella typhi (Ty800) is a safe and immunogenic single-dose typhoid fever vaccine in volunteers. J Infect Dis 1996;173:1408-14.

3. Hoa NT, Diep TS, Wain J, Parry CM, Hien TT, Smith MD, et al. Community-acquired septicaemia in southern Viet Nam: the importance of multidrug-resistant Salmonella typhi. Trans R Soc Trop Med Hyg 1998;92: 503-8.

4. Levine MM, Taylor DN, Ferrecio C. Typhoid vaccines come of age. Pediatr Infect Dis J 1989;8:374-81.

5. Jones B, Falkow S. Salmonellosis: host immune responses and bacterial virulence determinants. Ann Rev Immunol 1996;14:533-61.

6. Ivanoff $\mathbf{B}$, Levine $\mathbf{M M}$, Lambert PH. Vaccination against typhoid fever: present status. Bull WHO 1994; 72:957.

7. Sinha A, Sazawal S, Kumar R, Sood S, Reddaiah VP, Singh B, et al. Typhoid fever in children aged less than 5 years. Lancet 1999;354:734-7.

8. Martin SM, Hardgrett-Bean N, Tauxe RV. An atlas of Salmonella in the United States: serotype-specific surveillance 1968-1986. Atlanta, GA: Centers for Disease Control; 1987.

9. Rowe B, Ward LR, Threlfall EJ. Spread of multiresistant Salmonella typhi. Lancet 1990;336:1065.

10. Lee C. Pathogenicity islands and the evolution of bacterial pathogens. Infect Agents Dis 1996;5:1-7.

11. Darwin KH, Miller VL. Molecular basis of the interaction of Salmonella with the intestinal mucosa. Clin Microbiol Rev 1999;12:405-28.

12. Mills DM, Bajaj V, Lee CA. A 40 kb chromosomal fragment encoding Salmonella typhimurium invasion genes is absent from the corresponding region of the Escherichia coli K-12 chromosome. Mol Microbiol 1995; 15:749-59.

13. Groissman EA, Ochman H. Cognate gene clusters govern invasion of host epithelial cells by Salmonella typhimurium and Shigella flexneri. Embo J 1993;12:3779-87.

14. Beuzen CR, Banks G, Deiwick J, Hensel M, Holden DW. $\mathrm{pH}$-dependent secretion of SseB, a product of the SPI-2 type III secretion system of Salmonella typhimurium. Mol Microbiol 1999;33:806-16.

15. Vásquez-Torres A, Xu Y, Jones-Carson J, Holden DW, Lucia SM, Dinauer MC, et al. Salmonella pathogenicity island 2-dependent evasion of the phagocyte NADPH oxidase. Science 2000;238:1655-8.

16. Galen JE, Gómez-Duarte OG, Losonsky GA, Halpern JL, Lauderbaugh, CS, Kaintuck S, et al. A murine model of intranasal immunization to assess the immunogenicity of attenuated Salmonella typhi live vector vaccines in stimulating serum antibody responses to expressed foreign antigens. Vaccine 1997:15:700-8. 
17. Hopkins S, Kraehenbuhl J, Schöedel F, Potts A, Peterson D, de Grandi $P$, et al. A recombinant Salmonella typhimurium vaccine induces local immunity by four different routes of immunization. Infect Immun 1995;63:3279-86.

18. Sztein MB, Tanner MK, Polotsky Y, Orenstein JM, Levine MM. Cytotoxic T lymphocytes after oral immunization with attenuated vaccine strains of Salmonella typhi in humans J Immunol 1995;155:398793.

19. VanCott JL, Staats HF, Pascual DW, Roberts M, Chatfield SN, Yamamoto M, et al. Regulation of mucosal and systemic antibody responses by $T$ helper subsets, macrophages, and derived cytokines following oral immunization with live recombinant Salmonella. J Immnunol 1997;156:1504-14.

20. Sztein MB, Wasserman SS, Tacket CO, Edelman $\mathrm{R}$, Hone D, Lindberg AA, et al. Cytokine production patterns and lymphoproliferative responses in volunteers orally immunized with attenuated vaccine strains of Salmonella typhi. J Infect Dis 1994;170:150817.

21. Comoy EE, Capron A, Thyphronitis G. In vivo induction of type 1 and 2 immune responses against protein antigens. Inter Immunol 1997;9:523-31.

22. González C, Hone D, Noriega F, Tacket CO, Davis JR, Losonsky G, et al. Salmonella typhi vaccine strain CVD 908 expressing the circumsporozoite protein of Plasmodium falciparum: strain construction and safety and immunogenicity in humans. J Infect Dis 1994;169:927-31.

23. Mastroeni $P$, Simmons $C$, Fowler R, Hormaeche CE, Dougan G. Igh-6-/- (B-cell-deficient) mice fail to mount solid acquired resistance to oral challenge with virulent Salmonella enterica serovar Typhimurium and show impaired Th1 T-cell responses to Salmonella antigens. Infect Immun 2000;68:46-53.

24. Levine, MM, Tacket CO, Galen JE, Barry EM, Noreiga F, Sztein MB. Progress in development of new attenuated strains of Salmonella typhi as live oral vaccines against typhoid fever. In: Levine MM, Woodrow GC, Kaper JB, Cobon GS, editors. New generation vaccines. New York: Marcel Dekker; 1997. p.437-46.

25. Bodhidatta L, Taylor DN, Thisyakorn U, Echeverria P. Control of typhoid fever in Bankok, Thailand, by annual immunization of school children with parenteral typhoid vaccine. Rev Infect Dis 1987;9:841-5.

26. Hessel L, Debois H, Fletcher M, Dumas R. Experience with Salmonella typhi Vi capsular polysaccharide vaccine. Eur J Clin Microbiol Infect Dis 1999;18:609-20.

27. Kossaczka Z, Lin FC, Ho VA, Thuy NT, Bay PV, Thanh TC, et al. Safety and immunogenicity of Vi conjugate vaccines for typhoid fever in adults, teenagers, and 2- to 4-year-old children in Vietnam. Infect Immun 1999; 67:5806-10.

28. Levine MM, Ferrecio C, Black RE, Germanier R. Large-scale field trial of Ty21a live oral typhoid vaccine in enteric-coated capsule formulation. Lancet 1987; 1:1049-52.

29. Levine MM, Ferrecio C, Cryz S, Ortiz E. Comparison of enteric-coated capsules and liquid formulation of Ty21a typhoid vaccine in randomised controlled field trial. Lancet 1990;336:891-4.

30. Simunjuntak C, Paleologo F, Punjabi NH, Darmowigoto $\mathrm{R}$, Soeprawoto, Totosudirjo $\mathrm{H}$, et al. Oral immunization against typhoid fever in Indonesia with Ty21a vaccine. Lancet 1991;338:1055-9.

31. Hoiseth S, Stocker BAD. Aromatic-dependent Salmonella typhimurium are non-virulent and effective as live vaccines. Nature 1981;292:238-9.

32. Hone DM, Harris AM, Chatfield SN, Dougan G, Levine MM. Construction of genetically defined double aro mutants of Salmonella typhi. Vaccine 1991;9:8106.

33. Medina E, Paglia P, Nikolaus T, Müller A, Hensel M, Guzman CA. Pathogenicity island 2 mutants $0^{\circ} \mathrm{f}$ Salmonella typhimurium are efficient carriers for heterologous antigens and enable modulation of immune responses. Infect Immun 1999;67:1093-9.

34. Tacket CO, Sztein MB, Losonsky GA, Wasserman SS, Nataro JP, Edelman R, et al. Safety and immune response in humans of live oral Salmonella typhi vaccine strains deleted in htrA and aroC, aroD. Infect Immun 1997; 65:452-6.

35. Curtiss RIII, Kelly SM. Salmonella typhimurium deletion mutant lacking adenylated cyclase and cyclin AMP receptor protein are avirulent and immunogenic. Infect Immun 1987;55:3035-43.

36. Chatfield SN, Strugnell RA, Dougan G. Live Salmonella as vaccines and carries of foreign antigenic deterninants. Vaccine 1989;7:495-8.

37. Dunstan SJ, Simmons CP, Strugnell RA. Use of in vivo-regulated promoters to deliver antigens from attenuated Salmonella enterica var. Typhimurium. Infect Immune 1999;67:5133-41.

38. Chatfield SN, Charles IG, Makoff AF, Oxer MD, Dougan G, Pickard D, et al. Use of the nirB promoter to direct the stable expression of heterologous antigens in Salmonella oral vaccine strains: development of a single-dose oral tetanus vaccine. Biotechnology 1992:10:888-92.

39. Pickett TE, Pasetti MF, Galen JE, Sztein MB, Levine $M M$. In vivo characterization of the murine intranasal model for assessing the immunogenicity of attenuated Salmonella enterica serovar Typhi strains as live mucosal vaccines and as live vectors. Infect Immun 2000;68:205-13. 
40. Rolf JM, Gaudin HM, Eidels L. Localization of the diphtheria toxin receptor-binding domain to the carboxyl terminal Mr 6000 region of the toxin. J Biol Chem 1990; 265:7331-7.

41. Gómez-Duarte OG, Galen JE, Chatfield SN, Rappuoli R, Eidels L, Levine MM. Expression of fragment $C$ of tetanus toxin fused to a carboxyl-terminal fragment of diphtheria toxin in Salmonella typhi CVD 908 vaccine strain. Vaccine 1995;13:1596-602.

42. Barry EM, Gómez-Duarte OG, Chatfield SN, Pizza M, Rappuoli R, Losonsky GA, et al. Expression and immunogenicity of pertussis toxin $\mathrm{S} 1$ subunit-tetanus toxin fragment $\mathrm{C}$ fusions in Salmonella typhi vaccine strain CVD 908. Infect Immun 1996;64:4172-81.

43. NIH consensus development on Helicobacter pylori in peptic ulcer disease. Helicobacter pylori in peptic ulcer disease. JAMA 1994;272:65.

44. Parsonet J, Hanssen S, Rodríguez L, Gelb AB, Warnke RA, Jellum E, et al. Helicobacter pylori infection and gastric lymphoma. N Engl J Med 1994; $330: 1267-71$.

45. Hussel T, Isascson PG, Crabtree JE, Spencer J. The response of cells from low-grade B-cell gastric lymphomas of mucosa-associated lymphoid tissue to Helicobacter pylori. Lancet 1993;342:571-4.

46. Wotherspoon AC, Doglioni C, Cooper M, Robinson J. Regression of primary low-grade B-cell gastric lymphoma of mucosa-associated lymphoid tissue type after eradication of Helicobacter pylori. Lancet 1993;342:575-7.

47. Eaton KA, Krakowaka S. Effect of gastric $\mathrm{pH}$ on urease-dependent colonization of gnobiotic piglets by Helicobacter pylori. Infect Immun 1994;62:3604-7.

48. Tsuda M, Karita M, Morshed MG, Okita K, Nakasaki TA. A urease-negative mutant of Helicobacter pylori constructed by allelic exchange mutagenesis lacks the ability to colonize the nude mice stomach. Infect Immun $1994 ; 62: 3586-9$.

49. Marchetti M, Aricò B, Burroni D, Figura N, Rapuolli R, Ghiara P. Development of a mouse model of Helicobacter pylori infection that mimics human disease. Science 1995;655-8.

50. Michetti P, Corthésy-Theulaz I, Davin C, Haas R, Vaney AC, Heitz M, et al. Immunization of BALB/C mice against Helicobacter felis infection with Helicobacter pylori urease. Gastroenterology 1994;107:1002-11.

51. Pappo J, Thomas WD, Kabok Z, Taylor NS, Murphy JC, Fox JG. Effect of oral immunization with recombinant urease on murine Helicobacter felis gastritis. Infect Immun 1995;63:1246-52.

52. Mobley HL, Island MD, Hausinger RP. Molecular biology of microbioal ureases. Microbial Rev 1995;59:451-80.
53. Gómez-Duarte OG, Lucas B, Yan Z, Panthel K, Haas R, Meyer TF. Urease subunits A and B delivered by attenuated Salmonella typhimurium vaccine strain protects mice against gastric colonization by Helicobacter pylori. Vaccine 1998;16:460-71.

54. Gómez-Duarte OG, Bumann D, Meyer T. The attenuated Salmonella vaccine approach for the control of Helicobacter pylori-related diseases. Vaccine 1999; 17:1667-73.

55. World Health Organization. Malaria fact sheet no. 94. Geneve, Switzerland: World Health Organization; 1994.

56. Su X, Kirkman LA, Fujioka H, Wellems TE. Complex polymorphisms in an $330 \mathrm{kDa}$ protein are linked to chloroquine-resistant $P$. falciparum in Southeast Asia and Africa. Cell 1997;91:593-603.

57. Wernsdorfer WH. Epidemiology of drug resistance in malaria. Acta Trop 1994;56:143-56.

58. Roberts DJ, Craig AG, Berendt AR, Pinches R, Nash G, Marsh K, et al. Rapid switching to multiple antigenic and adhesive phenotypes in malaria. Nature 1992;357:689-92.

59. Conway DJ, Roper C, Oduola AM, Arnot DE, Kremsner PG, Grobush MP, et al. High recombination rate in natural populations of Plasmodium falciparum. Proc Natl Acad Sci USA 1999;96:4506-11.

60. Miller LH, Good MF, Milon G. Malaria pathogenesis. Science 1994;264:1878-83.

61. Christophers SR. The mechanism of immunity against malaria in communities living under hyper-endemic conditions. Indian J Med Res 1924;12:273-94.

62. Clyde DF, Most H, McCarthy V, Vandenberg JP. Immunization of man against sporozite-induced falciparum malaria. Am J Med Sci 1973;266:169-77.

63. Herrington D, Davis J, Nardin E, Beier M, Cortese $\mathrm{J}$, Eddy $\mathrm{H}$, et al. Successful immunization of humans with irradiated malaria sporozoites: humoral and cellular responses of the protected individuals. Am J Trop Med Hyg 1991;45:539-47.

64. Nussenzweig RS, Long CA. Malaria vaccines: multiple targets. Science 1994;265:1381-3.

65. Khusmith S, Charoenvit Y, Kumar S, Sedegah M, Beaudoin RL, Hoffmann SL. Protection against malaria by vaccination with sporozoite surface protein 2 plus CS protein. Science 1991;252:715-8.

66. Daly TM, Long CA. Humoral response to a carboxylterminal region of the merozoite surface protein- 1 plays a predominant role in controlling blood-stage infection in rodent malaria. J Immunol 1995;155:236-43.

67. Krzych U, Lyon AJ, Jareed T, Schneider I, Hollingdale MR, Gordon DM, et al. T lymphocytes from volunteers immunized with irradiated $P$. falciparum 
sporozoites recognize liver and blood stage malaria antigens. J Immunol 1995;155:4072-7.

68. Santiago A, Gómez-Duarte OG, Levine MM. Expression and secretion of the Plasmodium falciparum SSP2 protein in Salmonella vaccine strains by a type I secretion system. Chicago: American Society for Microbiology; 1999.

69. Gentschev I, Mollenkopf H, Sokolovic Z, Hess J, Kaufmann SH, Goebel W. Development of antigendelivery systems based on the Escherichia coli hemolysin secretion pathway. Gene 1996;179:13340 .

70. Hess J, Gentschev I, Miko D, Welzel M, Ladel C, Goebel W, et al. Superior efficacy of secreted over somatic antigen display in recombinant Salmonella vaccine induced protection against listeriosis. Proc Natl Acad Sci USA 1996;93:1458-63.

71. Connelly M, King CL, Bucci K, Walters S, Genton B, Alpers MP, et al. T-cell immunity to peptide epitopes of liver-stage antigen 1 in an area of Papua, New Guinea, in which malaria is holoendemic. Infect Immun 1997;65:5082-7.

72. Fidock DA, Gras-Masse H, Leppers J, Brahimi K, Benmohamed L, Mellouk S, et al. Plasmodium falciparum liver stage antigen- 1 is well conserved and contains potent $B$ and $T$ cell determinants. J Immunol 1994;153:190-204.

73. Gómez-Duarte OG, Pasetti MF, Santiago A, Hoffman S, Sztein MB, Levine MM. Expression of LSA-1 of Plasmodium falciparum in attenuated Salmonella vectors induce cellular and humoral immune responses in mice. Memoirs, XV International Congress for Tropical Medicine and Malaria; 2000; en prensa.
74. Becker SI, Wang R, Hedstrom RC, Aguiar JC, Jones TR, Hoffman SL, et al. Protection of mice against Plasmodium yoelii sporozoite challenge with $P$. yoelii merozoite surface protein 1 DNA vaccines. Infect Immun 1998;66:3457-61.

75. Blackman MJ, Heidrich HG, Donachie S, McBride JS, Holder AA. A single fragment of a malaria merozoite surface protein remains on the parasite during red cell invasion and is the target of invasion-inhibiting antibodies. J Exp Med 1990;172:379-82.

76. Blackman MJ, Scott-Finnigan TJ, Shai S, Holder AA. Antibodies inhibit the protease-mediated processing of a malaria merozoite surface protein. J Exp Med 1994;180:389-93.

77. Barale J, Blisnick T, Fujioka H, Alzari PM, Aikawa M, Braun-Breton C, et al. Plasmodium falciparum subtilisin-like protease 2, a merozoite candidate for the merozoite surface protein 1-42 maturase. Proc Natl Acad Sci USA 1999;96:6445-50.

78. Holder AA, Freeman RR. The three major antigens on the surface of Plasmodium falciparum merozoites are derived from a single high molecular weight precursor. J Exp Med 1984;160:624-9.

79. Wu S, Beier M, Sztein MB, Galen JE, Pickett T, Holder A, et al. Construction and immunogenicity in mice of an attenuated Salmonella typhi expressing Plasmodium falciparum merozoite protein-1 (MSP-1) fused to fragment $C$ of tetanus toxin. J Biotechnol 2000; en prensa.

80. Darji A, Guzmán CA, Gerstel B, Wachholz P, Timmis $\mathrm{KN}$, Wehland $\mathrm{J}$, et al. Oral somatic transgene vaccination using attenuated $S$. typhimurium. Cell 1997;91:765-75. 